\title{
Influence of Microstructural Evolution on the Hot Deformation Behavior of an Fe-Mn-Al Duplex Lightweight Steel
}

\author{
Li-Xiong $\mathrm{Xu}^{1} \cdot$ Hui-Bin $\mathrm{Wu}^{1,2} \cdot$ Xin-Tian Wang ${ }^{1}$
}

Received: 30 March 2017/Revised: 12 May 2017/Published online: 26 September 2017

(C) The Chinese Society for Metals and Springer-Verlag GmbH Germany 2017

\begin{abstract}
The hot deformation behavior of Fe-26Mn-6.2Al-0.05C steel was studied by experimental hot compression tests in the temperature range of $800-1050{ }^{\circ} \mathrm{C}$ and strain rate range of $0.01-30 \mathrm{~s}^{-1}$ on a Gleeble-3500 thermal simulation machine. The microstructural evolution during the corresponding thermal process was observed in situ by confocal laser scanning microscopy. Electron backscattered diffraction and transmission electron microscopy analyses were carried out to observe the microstructural morphology before and after the hot deformation. Furthermore, interrupted compression tests were conducted to correlate the microstructural characteristics and softening mechanisms at different deformation stages. The results showed that hot compression tests of this steel were all carried out on a duplex matrix composed of austenite and $\delta$-ferrite. As the deformation temperature increased from 800 to $1050{ }^{\circ} \mathrm{C}$, the volume fraction of austenite decreased from $70.9 \%$ to $44.0 \%$, while that of $\delta$-ferrite increased from $29.1 \%$ to $56.0 \%$. Due to the different stress exponents $(n)$ and apparent activation energies $(Q)$, the generated strain was mostly accommodated by $\delta$-ferrite at the commencement of deformation, and then both dynamic recovery and dynamic recrystallization occurred earlier in $\delta$-ferrite than in austenite. This interaction of strain partitioning and unsynchronized softening behavior caused an abnormal hot deformation behavior profile in the $\mathrm{Fe}-\mathrm{Mn}-\mathrm{Al}$ duplex steel, such as yield-like behavior, peculiar work-hardening behavior, and dynamic softening behavior, which are influenced by not only temperature and strain rate but also by microstructural evolution.
\end{abstract}

KEY WORDS: Microstructural evolution; Dual-phase steel; Lightweight component; Hot deformation; Dynamic recrystallization

Available online at http://link.springer.com/journal/40195

Hui-Bin Wu

whbustb@163.com

1 Collaborative Innovation Center of Steel Technology, University of Science and Technology Beijing, Beijing 100083, China

2 National Engineering Research Center of Advanced Rolling, University of Science and Technology Beijing, Beijing 100083, China

\section{Introduction}

Characterizing the hot deformation behavior of steels is the basis of the control rolling theory, which can not only provide optimized manufacturing methods and process parameters for enterprises, but also improve the microstructure and properties of steel after molding [1]. In a general sense, the hot deformation behavior of steel is mainly affected by factors, such as strain, strain rates, and deformation temperatures. In fact, high-temperature flow stress in the entire strain range depends on the combined effects of work hardening (WH), dynamic recovery (DRV), and dynamic recrystallization (DRX) [2]. Microstructural 
evolution related to phase proportion and morphology during hot working process will cause a non-negligible influence on the flow curves of steels, which is most often overlooked by researchers.

$\mathrm{Fe}-\mathrm{Mn}-\mathrm{Al}$ lightweight steel has gained much attention due to the combination of its excellent mechanical properties, improved corrosion resistance, and low density [3]. With different $\mathrm{Al} / \mathrm{Mn}$ equivalent ratios, this kind of steel could be distinguished into single ferrite, single austenite, and austenite-ferrite duplex structures [4]. During hot deformation, single ferrite steels are normally softened by intense DRV after a certain extent WH due to their high stacking fault energies. On the other hand, austenitic steels with relatively low stacking fault energy are softened by DRX [5]. Hence, the flow stress rises in the initial workhardening regime and then becomes constant in ferritic steels, whereas it reaches a maximum value before dropping to the steady state in austenitic steels [6,7]. In duplex steels, the dissimilar plastic behaviors and volume fractions of austenite and ferrite exhibit the complexity of the hot deformation behavior. Fan et al. [8] found that the strain was concentrated in the softer $\delta$-ferrite phase at the commencement of deformation and subsequently, austenite experienced the main strain. Balancin et al. [9] found that when the volume fraction of austenite was $<18 \%$, the mechanical behavior determined by the ferrite matrix shows softening due to continuous dynamic recrystallization. When the austenite volume fraction was near $50 \%$, the material tended to form a duplex structure and the flow curves displayed distinct work hardening and dynamic softening regions.

Recent research on the hot deformation behavior of $\mathrm{Fe}-$ $\mathrm{Mn}-\mathrm{Al}$ lightweight steels has mostly focused on the constitutive models of true stress-strain curves; however, only a few reports consider the influence of microstructure evolution on high-temperature flow behavior, especially for $\mathrm{Fe}-\mathrm{Mn}-\mathrm{Al}$ duplex lightweight steels [10-13]. Thus, this study aimed at understanding the hot deformation mechanism in this kind of steels. In order to investigate the effects of strain rates and temperatures on the flow stress, experimental hot compression tests were conducted on a Gleeble-3500 thermal simulation machine in the temperature range of $800-1050{ }^{\circ} \mathrm{C}$ and strain rate range of $0.01-30 \mathrm{~s}^{-1}$. The microstructural evolution during the corresponding thermal process was observed in situ by confocal laser scanning microscopy (CLSM). Electron backscattered diffraction (EBSD) and transmission electron microscopy (TEM) were carried out to observe the microstructural morphologies before and after the hot deformation. Furthermore, interrupted compression tests were conducted to clearly correlate the microstructural characteristics and softening mechanisms at different deformation stages.

\section{Materials and Methods}

The steel used in the present study was melted and cast into a $25 \mathrm{~kg}$ ingot in a vacuum induction melting furnace. The composition of the steel is $0.05 \mathrm{wt} \% \mathrm{C}, 26.0 \mathrm{wt} \% \mathrm{Mn}$, $6.2 \mathrm{wt} \% \mathrm{Al}$, and $67.75 \mathrm{wt} \% \mathrm{Fe}$. After homogenization at $1150{ }^{\circ} \mathrm{C}$ for $2 \mathrm{~h}$, the ingot was forged into three billets with dimensions of $80 \mathrm{~mm} \times 80 \mathrm{~mm} \times 100 \mathrm{~mm}$ at 1000 $1100{ }^{\circ} \mathrm{C}$. During that period, the material was slightly wrought at an average forging ratio of 1.25 . As calculated by Thermo-Calc software, the density of this $\mathrm{Fe}-\mathrm{Mn}-\mathrm{Al}$ steel was $6.98 \mathrm{~g} / \mathrm{cm}^{3}$, which is $11.6 \%$ lower than that of pure iron.

Samples of $\Phi 10 \mathrm{~mm} \times 15 \mathrm{~mm}$ were cutoff from the forged billets for unidirectional axisymmetrical compression tests on a Gleeble-3500 thermal simulation machine. A thermocouple was welded to the longitudinal center of the specimen to monitor the temperature. The specimens were initially heated to $1100{ }^{\circ} \mathrm{C}$ at a rate of $5{ }^{\circ} \mathrm{C} \mathrm{s}^{-1}$, soaked for 2 min to completely homogenize the temperature field, and then cooled down to the predetermined deformation temperatures at a rate of $10^{\circ} \mathrm{C} \mathrm{s}^{-1}$. After holding isothermally for $20 \mathrm{~s}$ to maintain a uniform temperature distribution throughout the cylinders, the specimens were compressed at temperature ranging from 800 to $1050{ }^{\circ} \mathrm{C}$ and strain rate ranging from 0.01 to $30 \mathrm{~s}^{-1}$ with the total true strain of 0.6 . Furthermore, following the same thermal mechanical process, partial compression tests were interrupted at true strain of 0.025 (yield strain), 0.112, 0.3 (peak strain), and 0.6 (steady strain), respectively, at the deformation temperature of $900{ }^{\circ} \mathrm{C}$ and strain rate of $1 \mathrm{~s}^{-1}$, to correlate the deformation mechanism with the characteristics of the flow curves. Finally, in order to preserve the high-temperature structure after hot compression, all the specimens were cooled to the ambient temperature at a cooling rate of $30{ }^{\circ} \mathrm{C} \mathrm{s}^{-1}$.

After the compression tests, the microstructures of the central areas of the specimens were analyzed by EBSD using a field-emission scanning electron microscope (FESEM, Zeiss Ultra 55) at an acceleration voltage of $15 \mathrm{kV}$ with a step size of $0.25 \mu \mathrm{m}$. The dislocation and substructure of the interruptedly compressed samples were observed by using an energy-filtered transmission electron microscope (FEI Tecnai F20). The specimens prepared for EBSD were sectioned longitudinally and electro-polished for $15 \mathrm{~s}$ at a voltage and current of $15 \mathrm{~V}$ and $1.5 \mathrm{~A}$, respectively, in an electrolyte solution of 20/80 (v/v) perchloric acid and ethanol. The foil specimens for TEM were acquired from the center of the compressed cylinder transversely, thinned down to $50 \pm 10 \mu \mathrm{m}$ using a silicon carbide paper, and then polished in a twin-jet electro- 
polisher using a solution of $15 / 85(\mathrm{v} / \mathrm{v})$ perchloric acid and ethanol at $20 \mathrm{~V}$ and $-20{ }^{\circ} \mathrm{C}$ for $20-25 \mathrm{~s}$.

The CSLM in situ observations of the tested steel were conducted on an ultra-high-temperature confocal microscope (VL2000DX-SVF17SP), the detailed information of which can be found elsewhere [14]. Cylindrical samples with dimensions of $\Phi 7.5 \mathrm{~mm} \times 3 \mathrm{~mm}$ were machined from the forged billets and mirror polished before observation. The thermal process adopted for the high-temperature CLSM was similar to that in the compression tests, i.e., the specimens were heated to $1100{ }^{\circ} \mathrm{C}$ at a rate of $5{ }^{\circ} \mathrm{C} \mathrm{s}^{-1}$, held for $2 \mathrm{~min}$, and then cooled to the ambient temperature at $50{ }^{\circ} \mathrm{C} \mathrm{min}{ }^{-1}$ for simulating the subsequent cooling process before deformation during the hot compression test. Simultaneously, the live pictures of the microstructures, magnified up to $1000 \times$, were recorded at a rate of 60 frames per second. The phase volume fractions of each picture were obtained using the manual point count method, according to the ASTME criteria [15].

\section{Results}

\subsection{Mechanical Response}

In general, due to the combined effects of WH, DRV, and DRX, three stages can be found at the plastic deformation stage in common flow curves. The work-hardening stage shows an increasing flow stress but a decreasing rate, due to a higher $\mathrm{WH}$ rate than the DRV softening rate. The softening stage exhibits a peak stress followed by an obviously decreasing stress, which is caused by the intense softening effect of DRX. A steady stress is displayed during the steady stage owing to a balance between the dynamic softening and work hardening [16].

The true stress-strain curves obtained from the hot compression tests of the $\mathrm{Fe}-\mathrm{Mn}-\mathrm{Al}$ steel are depicted in Fig. 1, all curves in which were smoothed using the Origin Pro 8 software and the Savizky-Golay method with a point window $<30$ [17], to eliminate the interference of the inevitable experimental error.

It is evident that the flow stress increases with decreasing deformation temperature and increasing strain rate, which is similar to the phenomenon found in other studies [18]. However, the shape of the flow curves exhibits some abnormal characteristics when the deformation conditions are altered. At low temperatures, the flow curves exhibit an initial work hardening followed by a single broad stress peak and a slight declining flow, which is an indication of DRX. As the temperature increases, the initial work hardening becomes inconspicuous and the curves display a steady flow after reaching a peak value without obvious dynamic crystallization. Meanwhile, the yielding plateaus with pronounced upper and lower yield points are found at the commencement of the plastic deformation stage, as pointed out by black arrows in magnified areas in Fig. 1, which is an indication of yield-like behavior similar to the yield point elongation-like effect in a 2205 duplex stainless steel [19]. As the strain rates decrease, all of the characteristics mentioned above become more dramatic. At a strain rate of $30 \mathrm{~s}^{-1}$, the flow stress fluctuates after the yield plateau and exhibits a typical discontinuous workhardening phenomenon [20].

In order to describe the flow curves quantitatively, the characteristic stresses [yield stress $\left(\sigma_{\mathrm{y}}\right)$, peak stress $\left(\sigma_{\mathrm{p}}\right)$, and steady stress $\left.\left(\sigma_{\mathrm{s}}\right)\right]$ were obtained from the original true stress-strain curves. $\sigma_{\mathrm{y}}$ was calculated with the help of the MATLAB software using the method of stepwise mathematics in GB/T 228-2002, for which the detailed procedure can be found elsewhere $[21,22] . \sigma_{\mathrm{p}}$ and $\sigma_{\mathrm{s}}$ were derived from the peak points and steady points of each flow curve, according to the method proposed in earlier studies $[23,24]$. The dependence of the characteristic stresses on the deformation temperatures and strain rates is presented in Fig. 2, in which the peak-yield and peak-steady stresses represent the degree of work hardening and dynamic softening, respectively.

As shown in Fig. 2 that all of the characteristic stresses increase linearly with decreasing deformation temperatures and increasing strain rates. However, the increases of yield stress and peak stress are similar at high temperatures while diverge at low temperatures, indicating that the degree of work hardening changes significantly with a change in the deformation temperature. The steady stress and peak stress increase synchronously at all deformation conditions. This observation points to an abnormal phenomenon, in which the degree of dynamic softening changes inconspicuously as the deformation conditions alter [25]. All of these characteristics signify that the deformation temperatures and strain rates are not the only factors that affect the deformation behavior of the studied Fe-Mn-Al duplex steels.

The hyperbolic-sine equation (Eq. 1) is usually used to reflect the combined effects of deformation temperature $(T)$ and strain rate $(\dot{\varepsilon})$ on the flow stress $(\sigma)$ [26], where $Z$ is the Zener-Hollomon parameter, $R, A$, and are constants, $n$ is the stress exponent calculated using Eq. (2), and $Q$ is the apparent activation energy of deformation calculated using Eq. (3).

$$
\begin{aligned}
& Z=\dot{\varepsilon} \exp \left(\frac{Q}{R T}\right)=A[\sinh (\alpha \sigma)]^{n}, \\
& n=\left.\frac{\partial(\ln \dot{\varepsilon})}{\partial\{\ln [\sinh (\alpha \sigma)]\}}\right|_{T},
\end{aligned}
$$




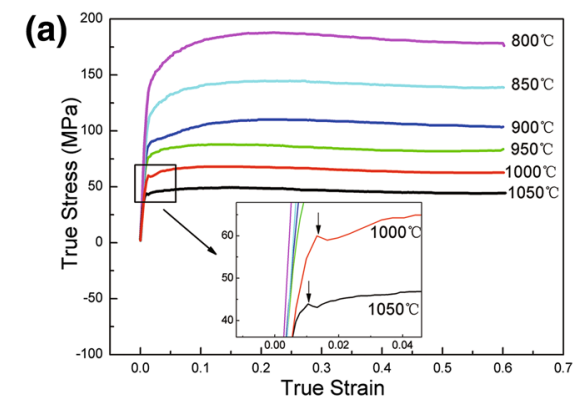

(c)

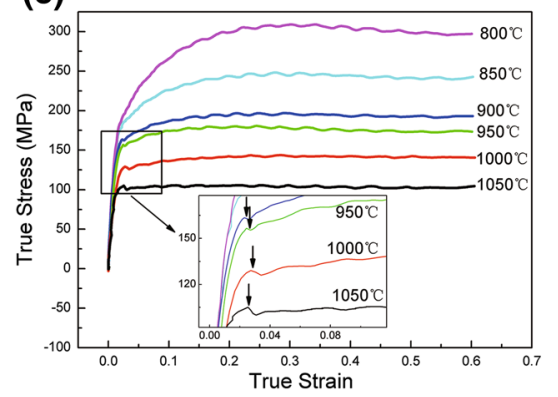

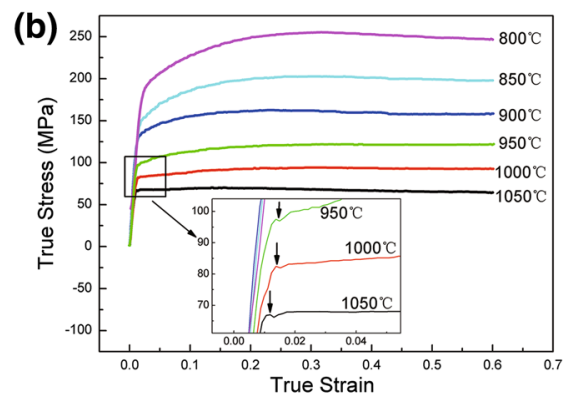

(d)

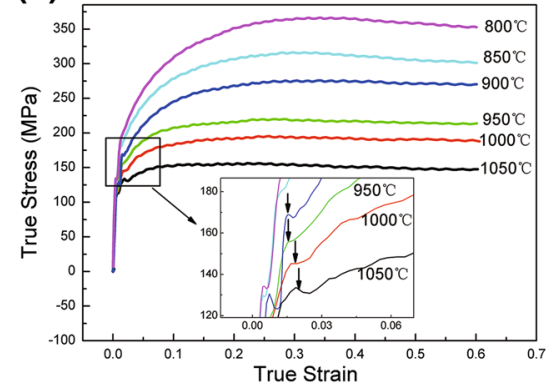

(e)

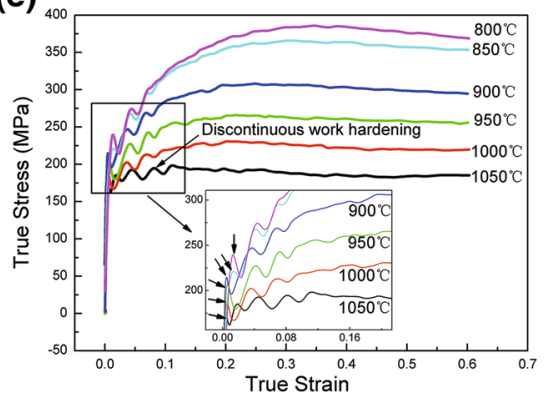

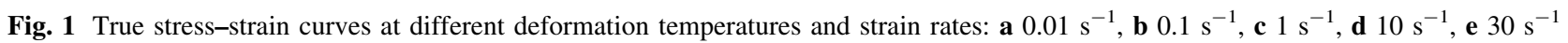
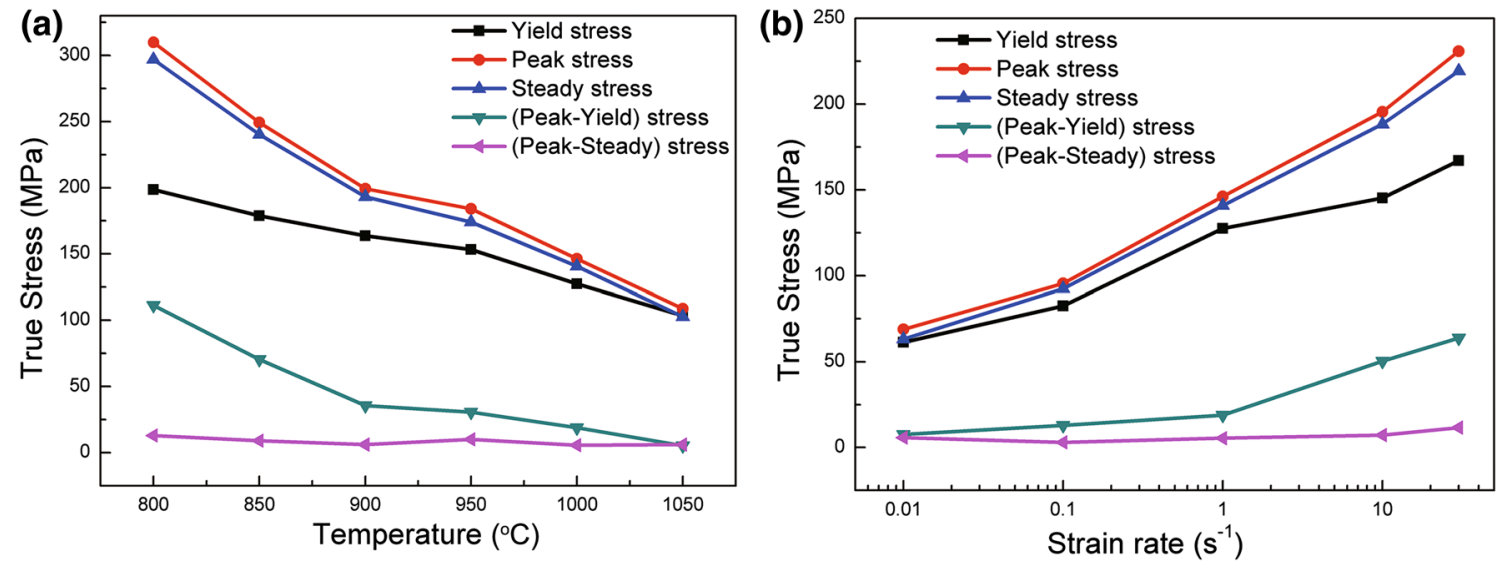

Fig. 2 Dependence of characteristic stresses on: a deformation temperatures at a strain rate of $1 \mathrm{~s}^{-1}$, b strain rates at a deformation temperature of $1000{ }^{\circ} \mathrm{C}$

$Q=\left.R n\left[\frac{\partial\{\ln [\sinh (\alpha \sigma)]\}}{\partial(1 / T)}\right]\right|_{\dot{\varepsilon}}$.

Generally, the values of $n$ and $Q$ in Eq. (1) are derived as the average values at different deformation conditions. Therefore, $\sigma$ was determined as a function of $T$ and $\dot{\varepsilon}$ alone in many studies. Actually, the stress exponent is an index of the workability, which reflects the deformation resistance of a material at different deformation conditions. The apparent activation energy is the energy provided by thermal and mechanical factors to overcome the barrier isothermally during hot deformation, so it is a reflection of the deformation resistance and the most dominant mechanism of materials during the hot deformation process, such as the DRV or the DRX. This means that the values of $n$ and $Q$ actually reflect the deformation mechanism, which are closely related to the microstructural characteristics of steels. Therefore, the values of both $n$ and $Q$ vary as the microstructure undergoes evolution in the duplex steels [27].

Substituting the peak stress and strain rates at all temperatures into Eq. (2), the values of $n$ were obtained from the slopes of the fitting lines of $\ln \dot{\varepsilon}$ vs $\ln [\sinh (\alpha \sigma)]$, as shown in Fig. 3a. According to the fact that the values of $n$ are distinctly smaller below $900{ }^{\circ} \mathrm{C}$ than above $900{ }^{\circ} \mathrm{C}$, the average values of $n$ at high $\left(>900{ }^{\circ} \mathrm{C}\right)$ and low $\left(\leq 900{ }^{\circ} \mathrm{C}\right.$ ) temperatures were calculated to be 3.81 and 3.12 , respectively. Substituting the peak stress and 
(a)

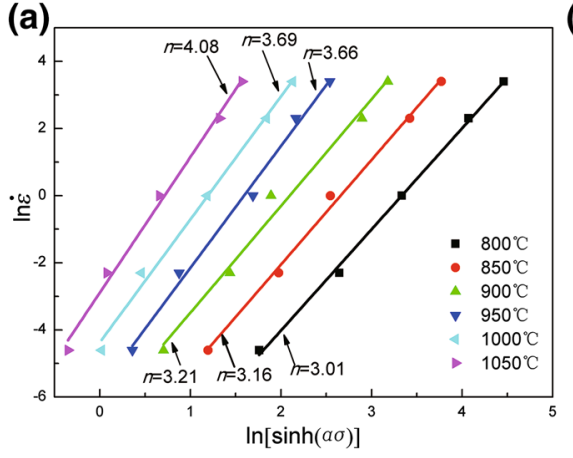

(b)

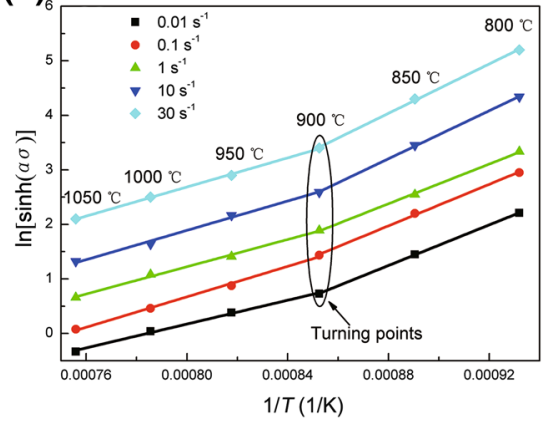

(c)

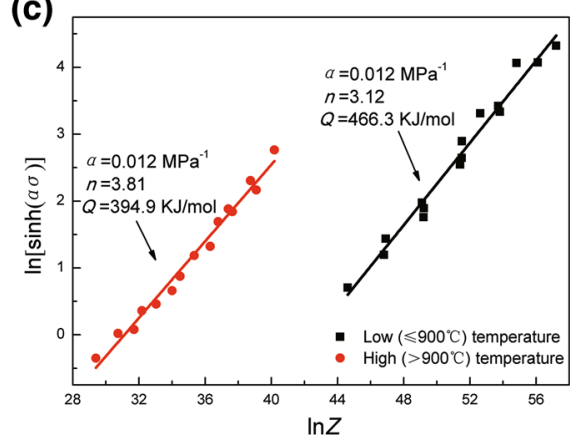

Fig. 3 Dependence of the peak stress on: a strain rates, $\mathbf{b}$ deformation temperatures, $\mathbf{c}$ the Zener-Hollomon parameters

temperatures at all strain rates into Eq. (3), the fitting lines of $\ln [\sinh (\alpha \sigma)$ vs $1 / T]$ are shown in Fig. 3b, in which the obvious turning points of the slopes were noticeable at temperature of $900{ }^{\circ} \mathrm{C}$ too. Hence, it is reasonable to assume that $900{ }^{\circ} \mathrm{C}$ is the border that distinguishes the deformation mechanism into high- and low-temperature regimes. Substituting the values of $n$ and the slopes of $\ln [\sinh (\alpha \sigma)$ vs $1 / T]$ into Eq. (3), the average values of $Q$ at high $\left(>900{ }^{\circ} \mathrm{C}\right)$ and low $\left(\leq 900{ }^{\circ} \mathrm{C}\right)$ temperatures were calculated to be 394.9 and $466.3 \mathrm{~kJ} \mathrm{~mol}^{-1}$, respectively. The consequent fitting relationship between the peak stress and the Zener-Hollomon parameter at high $\left(>900{ }^{\circ} \mathrm{C}\right)$ and low $\left(\leq 900{ }^{\circ} \mathrm{C}\right)$ temperatures is illustrated in Fig. 3c. All these parameters are indications of the different deformation mechanisms that are driven by the microstructural evolution as the deformation temperature varies [28].

\subsection{Microstructural Evolution}

As shown in Fig. 4, the SEM and EBSD analysis of the initial microstructure of the tested steel before hot compression indicates a typical duplex phase structure, with the discontinuous $\delta$-ferrite network distributed along the grain boundaries of the coarse equiaxed austenite. From the image of the grain boundaries (Fig. 4b), the average austenite grain size was calculated to be $22.1 \mu \mathrm{m}$ using the linear intercept method (ASTM E-112).

The CSLM in situ observation results are presented in Fig. 5. Due to the fast heating rate $\left(5^{\circ} \mathrm{C} \mathrm{s}^{-1}\right)$, there is no apparent transformation of either austenite or $\delta$-ferrite until the phases are held for $16 \mathrm{~s}$ at $1100{ }^{\circ} \mathrm{C}$, at which the new $\delta$ ferrite nuclei are generated at the grain boundaries of austenite (Fig. 5b). Upon holding for $2 \mathrm{~min}$ at $1100{ }^{\circ} \mathrm{C}$, the $\delta$-ferrite nuclei grow, along with an obvious decrease in the austenite content and a corresponding increase in the $\delta$ ferrite content (Fig. 5c). During the cooling process from 1100 to $800{ }^{\circ} \mathrm{C}$ at a rate of $50{ }^{\circ} \mathrm{C} \mathrm{min}{ }^{-1}$, the newly formed $\delta$-ferrite transforms into austenite gradually (Fig. $5 \mathrm{~d}-\mathrm{i}$ ).

Adopting the method of manual point count, the dependence of the austenite and $\delta$-ferrite volume fractions on the temperature during the cooling process has been analyzed (Fig. 6). As the temperature decreases from 1050 to $800{ }^{\circ} \mathrm{C}$, the volume fraction of $\delta$-ferrite decreases from $29.1 \%$ to $56.0 \%$, while that of austenite increases from $70.9 \%$ to $44.0 \%$. By combining these results with the analysis presented in Fig. 3, it is reasonable to conclude that the higher stress exponent and lower apparent activation energy at high temperatures $\left(>900{ }^{\circ} \mathrm{C}\right)$ result from the dominant deformation mechanism dominated by $\delta$-ferrite, and the opposite situation at lower temperatures
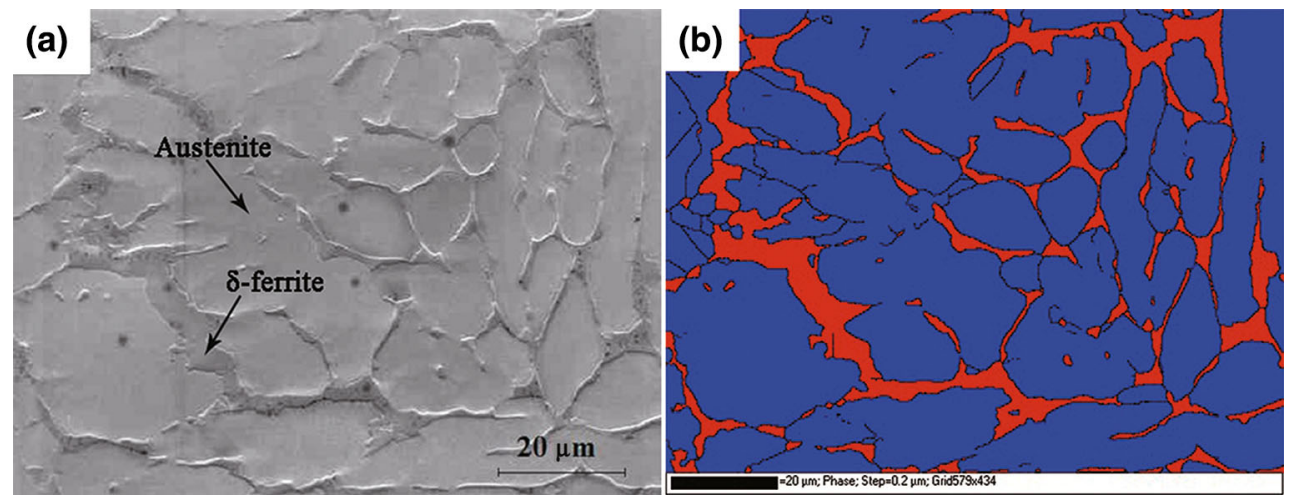

Fig. 4 Initial microstructure of the specimen before hot compression: a SEM image, $\mathbf{b}$ combined image of grain boundary map and color code phase map measured by the EBSD, with the austenite (fcc) shown in blue and $\delta$-ferrite (bcc) in red 

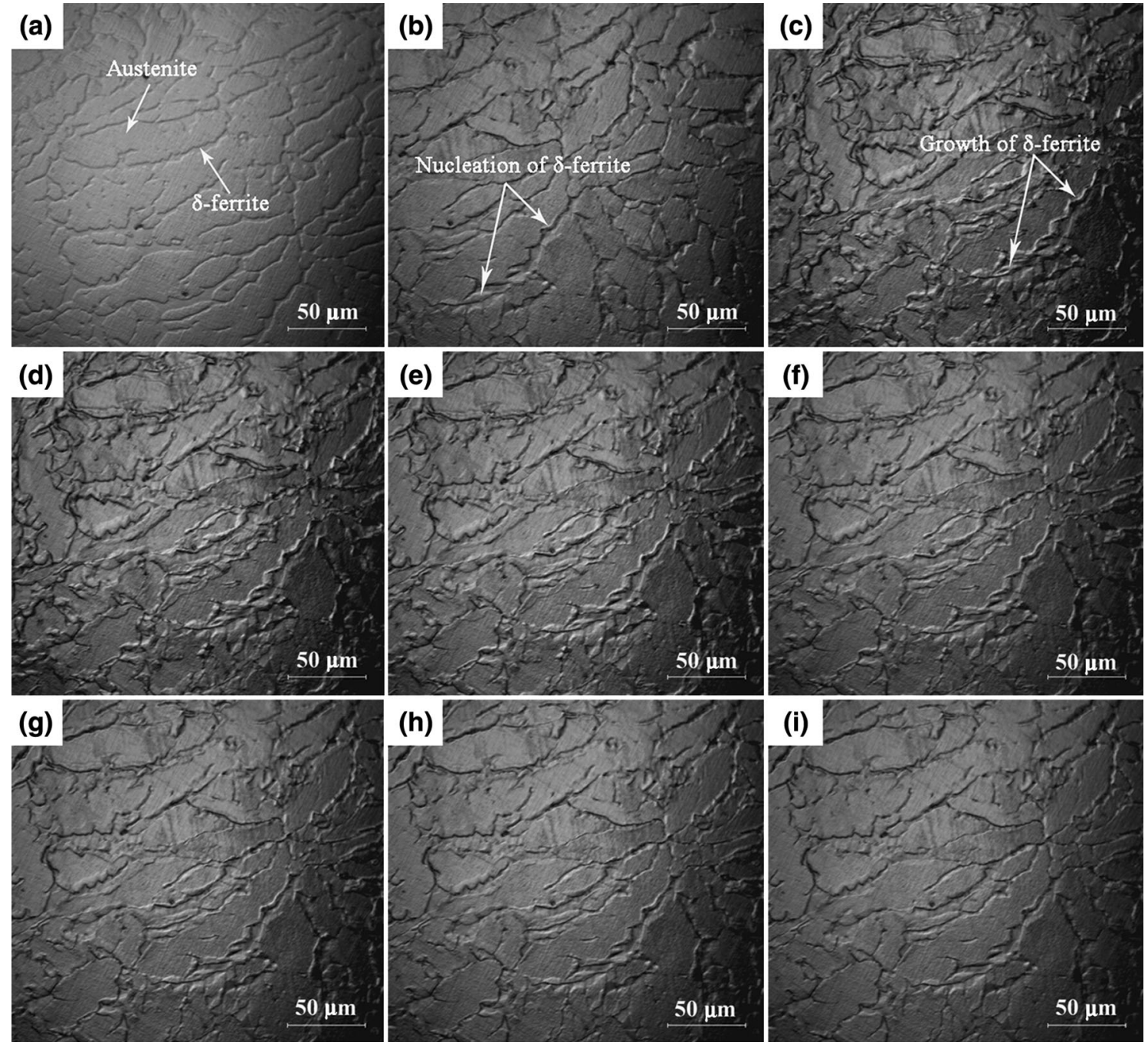

Fig. 5 CSLM in situ observations of the tested steel at a $0.03 \mathrm{~s}$ and $24.2{ }^{\circ} \mathrm{C}, \mathbf{b} 441.5 \mathrm{~s}$ and $1107.1{ }^{\circ} \mathrm{C}$, c $545.5 \mathrm{~s}$ and $1099{ }^{\circ} \mathrm{C}$, d $618.7 \mathrm{~s}$ and $1050.1{ }^{\circ} \mathrm{C}$, e $679.9 \mathrm{~s}$ and $1000.0{ }^{\circ} \mathrm{C}, \mathbf{f} 739.5 \mathrm{~s}$ and $950.0^{\circ} \mathrm{C}$, g $797.7 \mathrm{~s}$ and $900.0{ }^{\circ} \mathrm{C}, \mathbf{h} 858.6 \mathrm{~s}$ and $850.2{ }^{\circ} \mathrm{C}, \mathbf{i} 917.6 \mathrm{~s}$ and $800.3{ }^{\circ} \mathrm{C}$

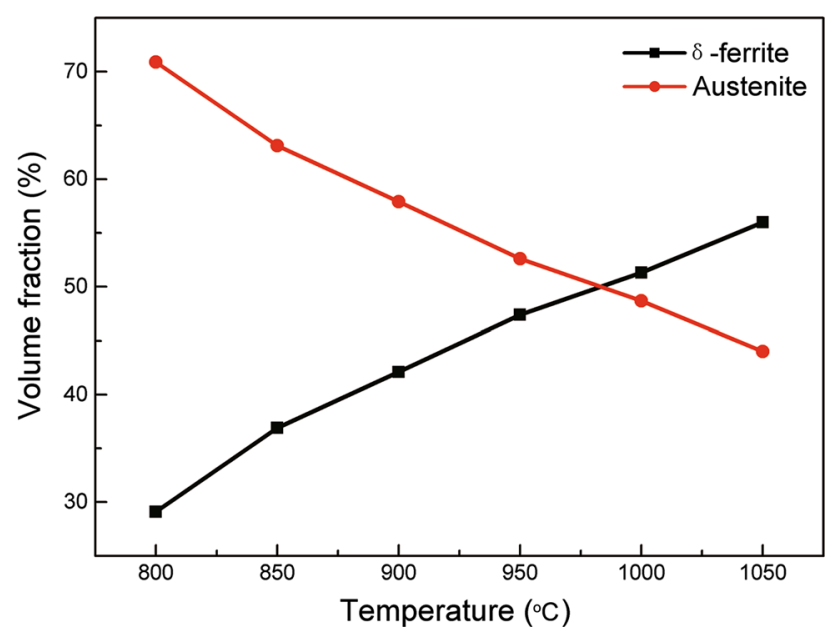

Fig. 6 Dependence of the volume fractions of austenite and $\delta$-ferrite on the temperature during the cooling process in CSLM testing
( $\leq 900{ }^{\circ} \mathrm{C}$ ) is attributed to the dominant austenite phase [29].

Figure 7 shows the EBSD analysis results of the duplex microstructure deformed at different temperatures and strain rates. At a strain rate of $0.01 \mathrm{~s}^{-1}$, partial tiny austenitic grains are distributed along the original austenite boundaries or inside the austenite grains at $850{ }^{\circ} \mathrm{C}$, thus showing a typical incomplete DRX in austenite [30]. The equiaxed high-angle boundaries ( $\mathrm{HABs}$, greater than $10^{\circ}$ ) are an indication of DRX in $\delta$-ferrite (Fig. 7a). The larger DRX grains in $\delta$-ferrite indicate that DRX occurs earlier in $\delta$-ferrite than in austenite. As the temperature increases to $950{ }^{\circ} \mathrm{C}$, the number of tiny DRX grains in austenite decreases abnormally and $\delta$-ferrite is distributed discretely in the austenite matrix (Fig. 7b), implying that the DRX process is suppressed in austenite while it is promoted in $\delta$ ferrite. As the temperature further increases to $1050{ }^{\circ} \mathrm{C}$, the partial DRX austenite grains grow into larger structures 

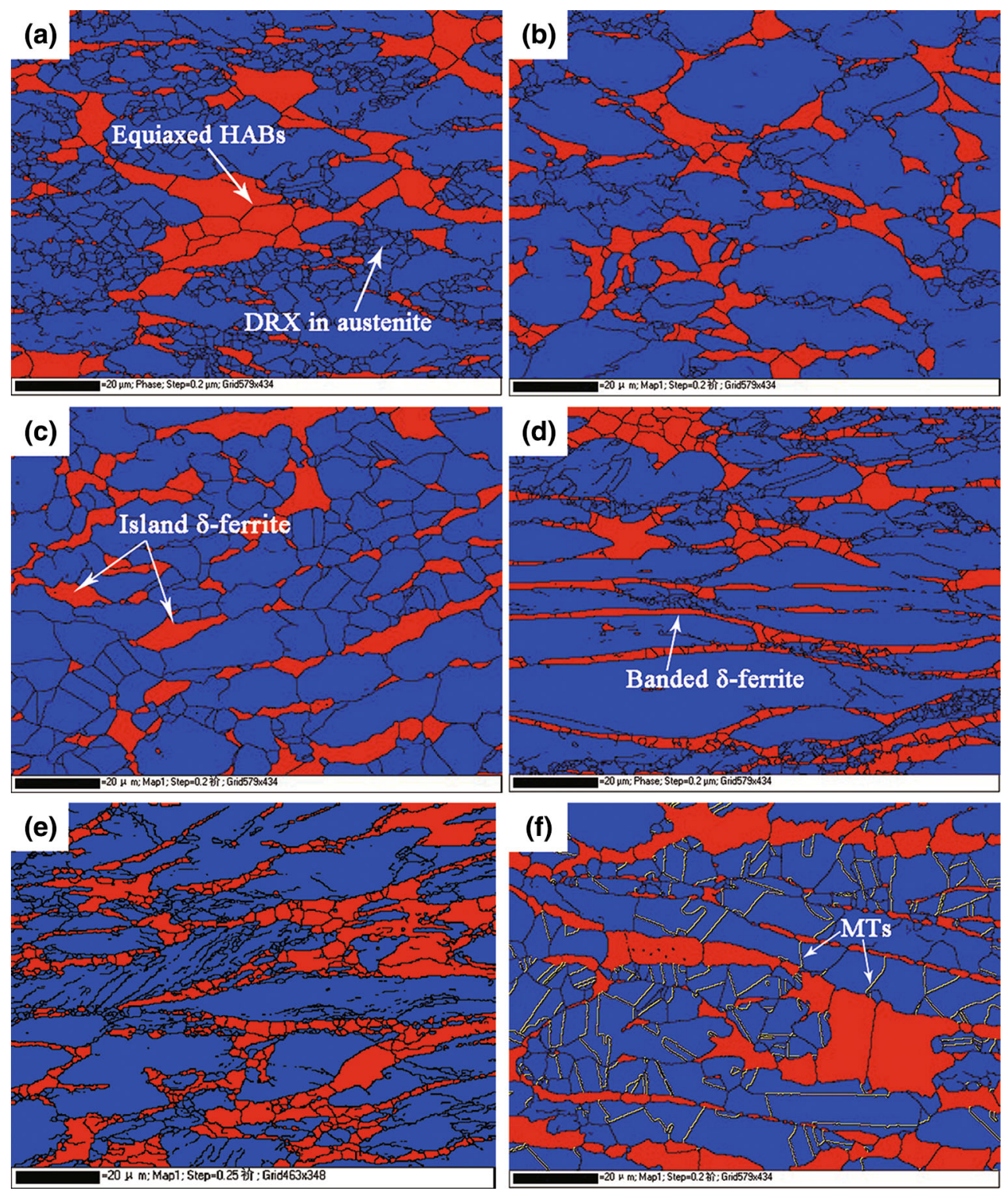

Fig. 7 EBSD analysis (showing austenite in blue, $\delta$-ferrite in red, HABs in black solid lines, and MTs in yellow solid lines) of the duplex microstructure of the specimens deformed at: a $0.01 \mathrm{~s}^{-1}$ and $850{ }^{\circ} \mathrm{C}, \mathrm{b} 0.01 \mathrm{~s}^{-1}$ and $950{ }^{\circ} \mathrm{C}, \mathrm{c}^{\circ} .01 \mathrm{~s}^{-1}$ and $1050{ }^{\circ} \mathrm{C}, \mathrm{d}^{\circ} 10 \mathrm{~s}^{-1}$ and $850{ }^{\circ} \mathrm{C}$, e $10 \mathrm{~s}^{-1}$ and $950{ }^{\circ} \mathrm{C}, \mathbf{f} 30 \mathrm{~s}^{-1}$ and $1050{ }^{\circ} \mathrm{C}$

and separate $\delta$-ferrite into island structures (Fig. 7c). Moreover, the non-dependence of phase proportions on the deformation temperatures indicates that a large fraction of $\delta$-ferrite has transformed into austenite during the cooling process.

As the strain rate increases to $10 \mathrm{~s}^{-1}$, DRX in both austenite and $\delta$-ferrite is postponed, leading to fewer tiny DRX grains in austenite and smaller DRX grains in $\delta$ ferrite (Fig. 7d, e). Simultaneously, due to the intense increase in work hardening, $\delta$-ferrite turns into discontinuous bands, which are perpendicular to the compression direction. As the strain rate further increases to $30 \mathrm{~s}^{-1}$, dislocation slip is hindered and a sharp increase in the deformation energy storage stimulates the occurrence of a large number of mechanical twins (MTs) in the original austenite grains, which are marked as solid yellow lines in Fig. 7f. Since there is no nucleation or growth of DRX grains in austenite because of the high strain rate, the $\delta$ ferrite bands are preserved even at a high temperature.

\section{Discussion}

The above microstructural evolution analysis indicates that the hot compression tests of the $\mathrm{Fe}-\mathrm{Mn}-\mathrm{Al}$ steel under investigation are essentially carried out on a duplex matrix 
composed of austenite and $\delta$-ferrite. As the temperature increases, the volume fraction of austenite decreases and that of $\delta$-ferrite increases and vice versa. The different stress exponents and apparent activation energies of austenite and $\delta$-ferrite cause the unsynchronized occurrence of DRV and DRX in the two phases, and further give rise to the unusual hot deformation characteristics of this $\mathrm{Fe}-\mathrm{Mn}-\mathrm{Al}$ duplex steel, such as yield-like behavior, peculiar work-hardening behavior and dynamic softening behavior, which are influenced by not only deformation temperature and strain rate but also microstructural evolution.

In order to correlate the microstructural characteristics and softening mechanisms at different deformation stages, interrupted hot compression tests were conducted at the predetermined deformation conditions described above. The true stress-strain curves are shown in Fig. 8, in which the depicted curves were smoothed using the same method followed in Fig. 1. As seen in the magnified area (inset) in Fig. 8, a yield point elongation-like effect (marked with black arrows) appears at the start of plastic deformation, similar to what was observed in Fig. 1. During the workhardening stage, the flow stress increases slowly to a maximum with an increase in the strain, with a total stress enhancement of $29.7 \mathrm{MPa}$. When the strain further increases to 0.6 , the flow stress decreases slightly with a dynamic softening degree of $6.9 \mathrm{MPa}$.

\subsection{Yield-Like Behavior}

Figure 9 shows the EBSD and TEM analysis results of the microstructure after the compression test interrupted at strain of 0.025 (yield strain). The distorted $\delta$-ferrite and undeformed austenite indicate that enough deformation and

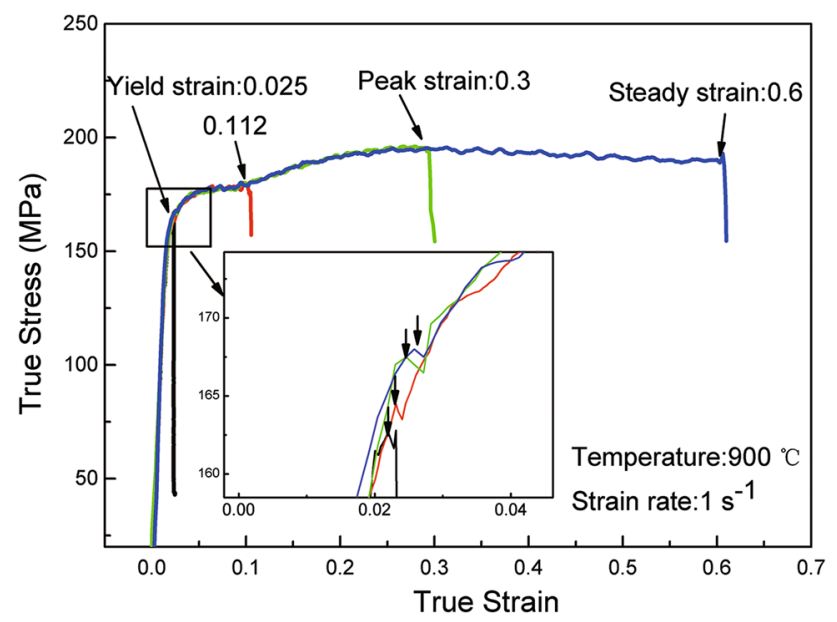

Fig. 8 True stress-strain curves of specimens interruptedly compressed at $900{ }^{\circ} \mathrm{C}$ and $1 \mathrm{~s}^{-1}$ at interrupted strains of $0.025,0.112,0.3$, and 0.6 work hardening are accommodated by $\delta$-ferrite at this point [31]. The concentrated distribution of low-angle boundaries (LABs, $<10^{\circ}$ ) on $\delta$-ferrite (Fig. 9a) signifies that the DRV in $\delta$-ferrite is the only softening mechanism at the commencement of deformation. This can be confirmed by the TEM image, which indicates a higher density of dislocations and the sub-boundary concentrating in $\delta$-ferrite.

The diffraction pattern of austenite in Fig. 9b indicates that the TEM observation was along the [001] zone axis of austenite, with the radio of $d_{\overline{2} 20}$ and $d_{020}$ (the value of $A / B$ ) as 1.409 , which near to the value of 1.414 in the facecentered cubic (fcc) crystal. The average $d$ spacing of $d_{01 \overline{1}}, d_{\overline{10} \overline{1}}$, and $d_{\overline{1} \overline{1} 0}$ (the value of $A$ ) in the diffraction pattern of ferrite was identified as $0.201 \mathrm{~nm}$, showing the typical [111] zone axis of body-centered cubic (bcc) crystal.

Generally, the diffusion rate in $\delta$-ferrite is about an order of magnitude higher than that in austenite. Further, the dislocation movement in $\delta$-ferrite is faster than that in austenite due to its higher stacking fault energy [32]; thus, the transfer of load to austenite is suppressed usually at the early stage of deformation [33]. However, the higher stacking fault energy also results in a relative ease for dislocations to climb or cross-slip as an expression of the lower apparent activation energy of $\delta$-ferrite, which leads to the formation of DRV and sub-grain microstructure, while delays the occurrence of DRX [34]. Consequently, the DRV in $\delta$-ferrite is primarily responsible for the yieldlike behavior of flow curves at high temperatures (as shown in Fig. 1).

At lower temperatures, the softening effect caused by DRV in $\delta$-ferrite is reduced due to the decreasing $\delta$-ferrite content (as shown in Fig. 6) and the lower atomic activity. Therefore, the yielding plateaus are substituted by the work-hardening effect at the commencement of plastic deformation. At lower strain rates, the time for strain concentration on $\delta$-ferrite is longer. The slow increase in dislocation density weakens the softening effect of DRV in $\delta$-ferrite and hence the yield-like behavior becomes inconspicuous [35], as shown in Fig. 1.

\subsection{Work-Hardening Behavior}

Figure 10 shows the EBSD and TEM analysis results of the specimen microstructure after the compression test interrupted at strains of 0.112 and 0.3 (peak strain). The diffraction pattern in Fig. 10b shows the same zone axis of austenite as Fig. 9b, with the value of $A / B$ as 1.411 . The diffraction pattern in Fig. 10d shows a typical [111] zone axis of ferrite, with the average value of $A$ as $0.203 \mathrm{~nm}$.

The occurrence of a large number of LABs in austenite (Fig. 10a) indicates that the load has been transferred from 

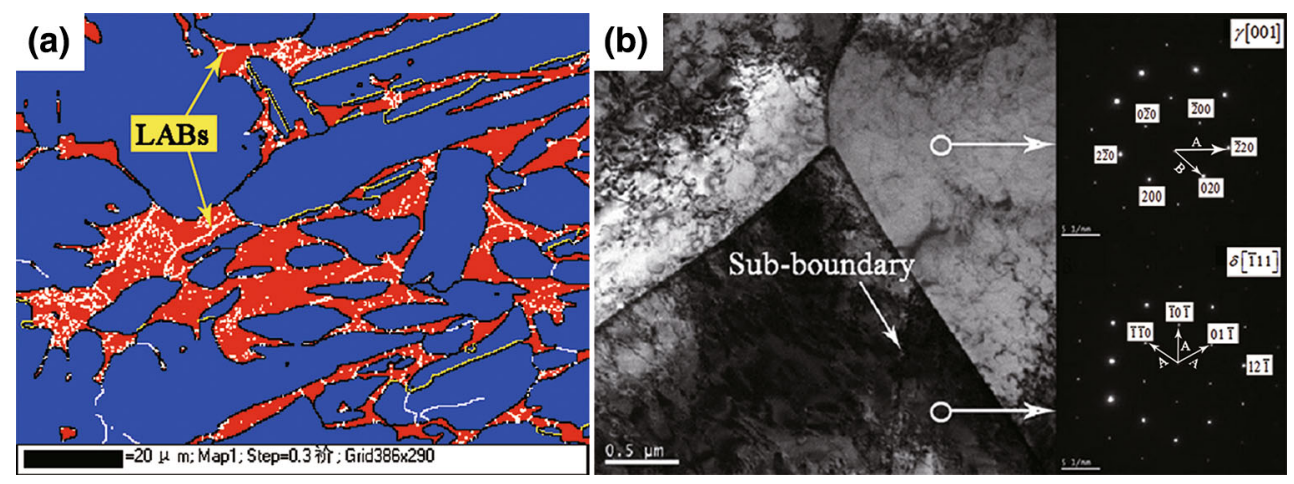

Fig. 9 a EBSD analysis (showing austenite in blue, $\delta$-ferrite in red, and LABs in white solid lines). b TEM image of the microstructure of the specimen after the compression was interrupted at a strain of 0.025
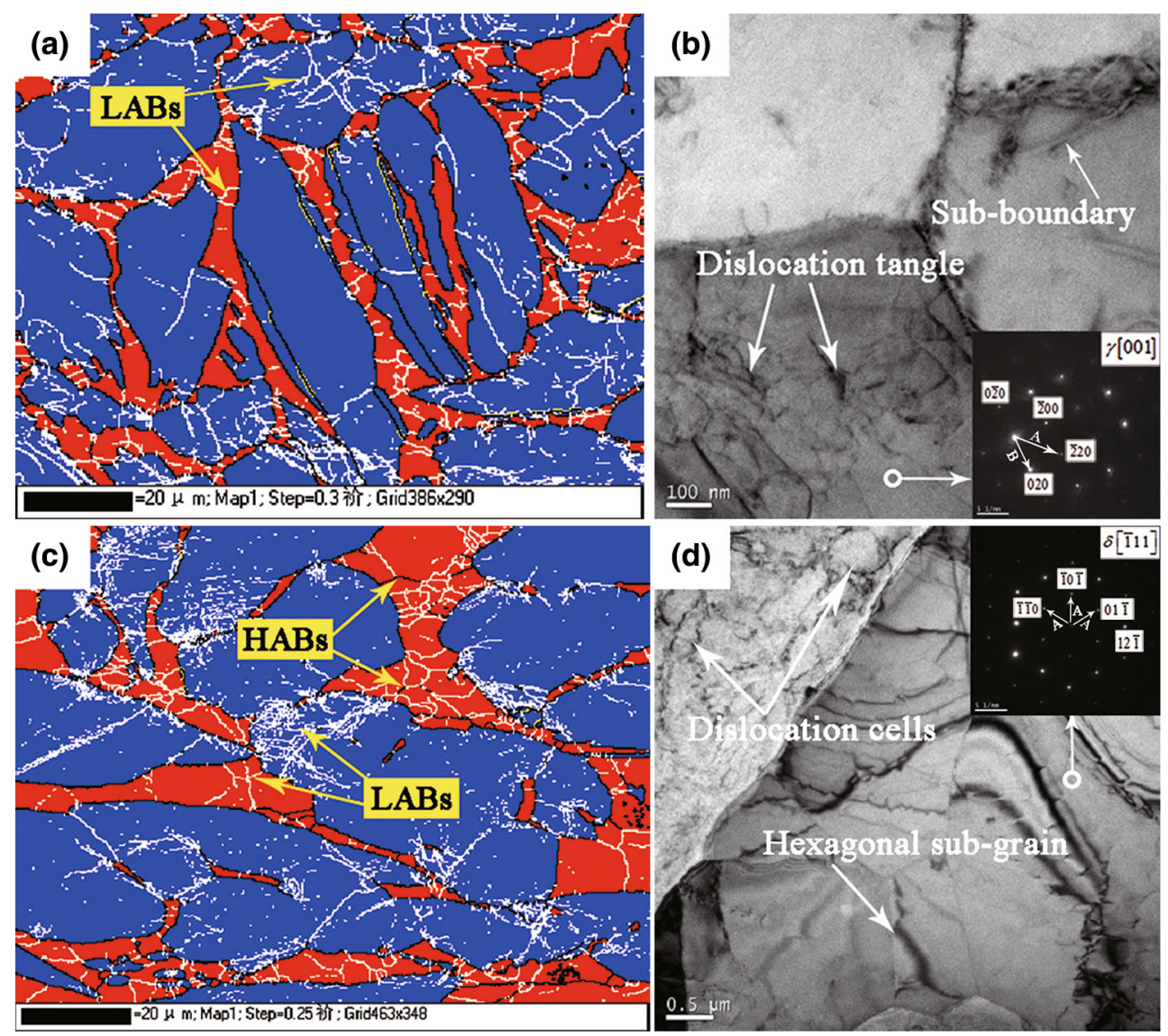

Fig. 10 EBSD analysis (showing austenite in blue, $\delta$-ferrite in red, LABs in white solid lines, and HABs in black solid lines) and TEM image of the microstructure after the compression was interrupted at strains of $\mathbf{a}, \mathbf{b} 0.112, \mathbf{c}, \mathbf{d} 0.3$

$\delta$-ferrite to austenite at the strain of 0.112 [36]. Then the rapid increase in the density of the dislocations in austenite (Fig. 10b) causes the initial work hardening, as shown in Fig. 8. Simultaneously, DRV in $\delta$-ferrite is enhanced, judging by the greater number of LABs compared with Fig. 9a, so that the degree of work hardening is not intense at this stage. As the true strain increases to 0.3 , the appearance of HABs in Fig. 10c indicates that DRX occurs in $\delta$-ferrite, which can be confirmed by the hexagonal subgrains in the TEM image (Fig. 10d). Meanwhile, the transition of irregular dislocation tangles into dislocation cells, as shown in Fig. 10d, indicates the occurrence of DRV in austenite [37]. Under the combined softening effect of DRX in ferrite and DRV in austenite, the work hardening is partially compensated and the flow stress increases to a maximum at a decreasing rate (Fig. 8). 

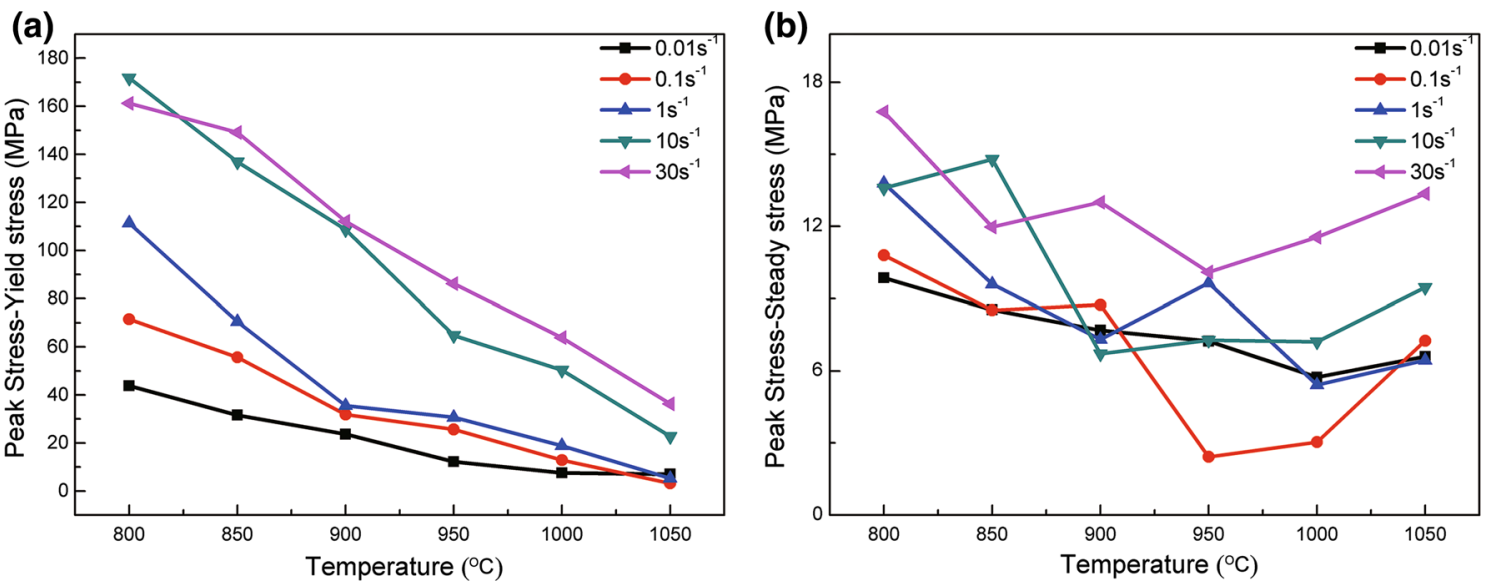

Fig. 11 Dependence of a work-hardening degree, $\mathbf{b}$ dynamic softening degree on the deformation temperatures and strain rates

According to the characteristic stresses obtained from the original true stress-strain curves, the dependence of the work-hardening degree (peak-yield stress) on the deformation temperatures and strain rates is shown in Fig. 11a.

At high deformation temperatures, more strain is concentrated on $\delta$-ferrite at the commencement of plastic deformation; the load that transfers from $\delta$-ferrite to austenite is lessened, which in turn alleviates the degree of work hardening. Moreover, the high temperature accelerates the occurrence of DRX in $\delta$-ferrite and DRV in austenite, which enhances the softening effect significantly. This combined effect results in a conspicuous reduction in the work-hardening degree as the deformation temperatures increases [38]. At high strain rates, it is difficult for DRX in $\delta$-ferrite and DRV in austenite to develop in a timely manner, whereas the dislocations in austenite reproduce quickly, and consequently, the degree of work hardening is intensified. Moreover, the discontinuous work-hardening phenomenon in Fig. 1e can be ascribed to the occurrence of the mechanical twins in the original austenite grains [39], as shown in Fig. 7f).

\subsection{Dynamic Softening Behavior}

Figure 12 shows the EBSD and TEM analysis results of the microstructure after the compression test interrupted at strain of 0.6 (steady strain). The diffraction pattern in Fig. 12b shows a typical [001] zone axis of austenite, with the value of $A / B$ as 1.413. Compared with Fig. 10, the greater number of equiaxed HABs in Fig. 12a signify that more complete DRX occurs in $\delta$-ferrite at the steady stage, and the partial tiny grains in austenite are indication of an incomplete DRX. The TEM image of the DRX grains in $\delta$ ferrite and austenite is shown in Fig. 12b. From these microstructures, it is reasonable to ascribe the slight declining of flow curves between the peak strain and steady strain regimes (Fig. 8) to the combined softening effect of a complete DRX in $\delta$-ferrite and an incomplete DRX in austenite [40].

In a general sense, the degree of dynamic softening (peak-steady stress) in flow curves increases with increasing deformation temperatures and decreasing strain rates [41]. However, in the case of the present $\mathrm{Fe}-\mathrm{Mn}-\mathrm{Al}$ duplex steels, the dependence of the dynamic softening degree on the deformation temperatures and strain rates is fluctuant (Fig. 11b).

Although the high temperatures are beneficial to atomic diffusion and dislocation movement, the larger proportion of $\delta$-ferrite at higher temperatures consumes more distortion energy before the softening stage, and consequently, the driving force for DRX is reduced [42, 43]. Therefore, the nucleation of DRX grains in austenite is inhibited even at an advantageous condition (as shown in Fig. 7b), and the degree of dynamic softening at high temperatures is not greater than that at low temperatures. At higher strain rates, although the DRX in $\delta$-ferrite and DRV in austenite are postponed at the work-hardening stage, the late DRX in $\delta$ ferrite subsequently plays an important role in the dynamic softening (Fig. $7 \mathrm{~d}-\mathrm{f}$ ), which leads to a comparable dynamic softening degree even under adverse conditions.

\section{Conclusions}

In this study, the deformation characteristics of a $\mathrm{Fe}-\mathrm{Mn}-$ Al duplex lightweight steel were investigated by hightemperature compression tests over a practical range of temperatures and strain rates. The influence of microstructural evolution on the flow behavior was studied by in situ observations using CSLM and EBSD as well as TEM. The microstructural characteristics and softening mechanisms at various deformation stages were analyzed by interrupted compression tests. The main conclusions are listed as follows: 

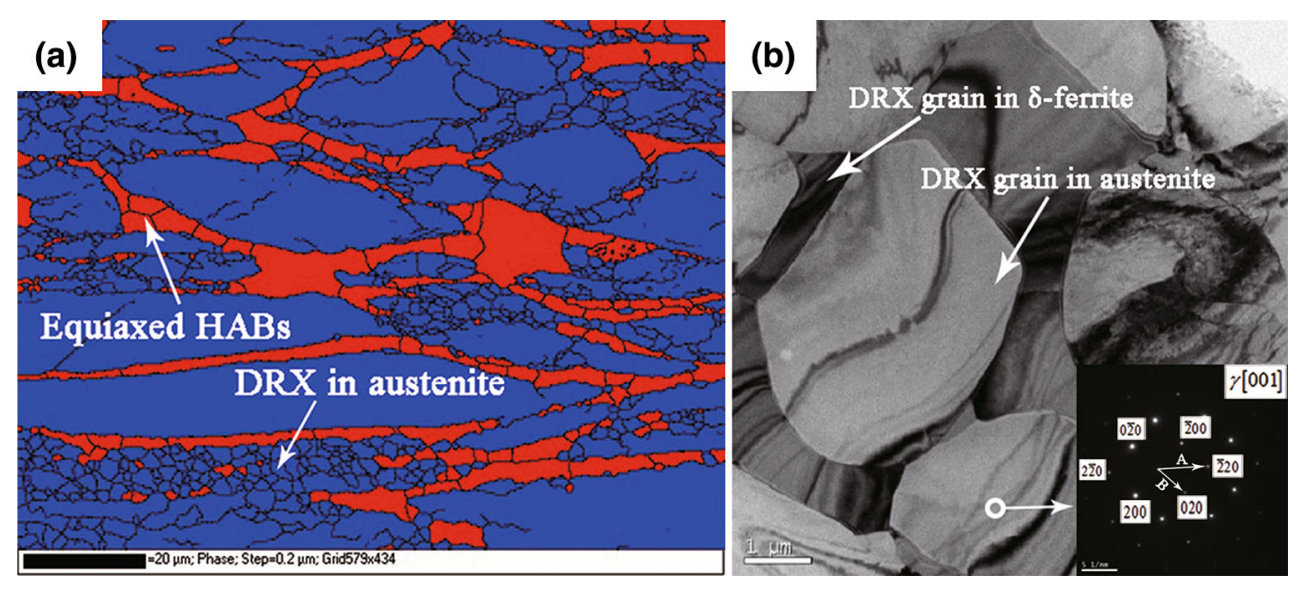

Fig. 12 a EBSD analysis (showing austenite in blue, $\delta$-ferrite in red, and HABs in black solid lines). b TEM image of the microstructure of the specimen after the compression was interrupted at a strain of 0.6

1. As the deformation temperatures increase from 800 to $1050{ }^{\circ} \mathrm{C}$, the volume fraction of austenite decreases from $70.9 \%$ to $44.0 \%$ while that of $\delta$-ferrite increases from $29.1 \%$ to $56.0 \%$.

2. Due to the higher stress exponent and lower apparent activation energy of $\delta$-ferrite as compared to austenite, the flow stress is mostly concentrated in $\delta$-ferrite during the early stages of deformation and then transferred to austenite. Therefore, the DRV and DRX processes occur earlier in $\delta$-ferrite than in austenite; this interaction of strain partitioning and unsynchronized softening behavior results in the abnormal characteristics of the flow curves.

3. The yield-like behavior at the commencement of plastic deformation is mainly due to the DRV in $\delta$ ferrite; the work-hardening behavior is caused by the functions of WH caused by the dislocation tangle in austenite; the dynamic softening behavior results from the combined softening effect of a complete DRX in $\delta$ ferrite and an incomplete DRX in austenite.

4. As the deformation temperatures increase, more distortion energy is consumed by the larger proportion of $\delta$-ferrite at the commencement of hot deformation, which lessens the load that transfers to austenite and reduces the subsequent driving force for DRV and DRX in austenite. Thus, at high temperatures, yieldlike behavior becomes more apparent, the workhardening degree obviously decreases, and the dynamic softening degree is not greater than that observed at low temperatures. At higher strain rates, the dislocation density increases quickly at the outset, which enhances the DRV in $\delta$-ferrite and further highlights the yield-like behavior. The DRV and DRX processes in austenite and $\delta$-ferrite, respectively, are postponed and thus the degree of work hardening is amplified. Subsequently, the late DRX in $\delta$-ferrite leads to a comparable dynamic softening degree even at adverse conditions.

Acknowledgement This research was financially supported by the National Natural Science Foundation of China (No. 51474031).

\section{References}

[1] W. Yu, L.X. Xu, Y. Zhang, B. Wang, C.Y. He, E.T. Dong, Trans. Mater. Heat Treat. 36(10), 261 (2015)

[2] L.J. Wang, W. Yu, H.B. Wu, Q.W. Cai, Q.G. Qi, Heat Treat. Met. 35(7), 5 (2010)

[3] C.H. Seo, K.H. Kwon, K. Choi, K.H. Kim, J.H. Kwak, S. Lee, N.J. Kim, Scr. Mater. 66(8), 519 (2012)

[4] Q. Yang, J.F. Wang, Y. Cong, L. Wang, Baosteel Technol. 3, 1 (2015)

[5] Q. Yang, J.F. Wang, Y. Cong, L. Wang, Baosteel Technol. 4, 1 (2015)

[6] Y.H. Yang, B. Yan, Mater. Sci. Eng. A 579, 194 (2013)

[7] L. Duprez, B.C. De Cooman, N. Akdut, Metall. Mater. Trans. A 33(7), 1931 (2002)

[8] G.W. Fan, J. Liu, P.D. Han, G.J. Qiao, Mater. Sci. Eng. A 515(1), 108 (2009)

[9] O. Balancin, W.A.M. Hoffmann, J.J. Jonas, Metall. Mater. Trans. A 31(5), 1353 (2000)

[10] D.J. Seol, Y.M. Won, T. Yeo, K.H. Oh, J.K. Park, C.H. Yim, ISIJ Int. 39(1), 91 (1999)

[11] A.S. Hamada, L.P. Karjalainen, M.C. Somani, R.M. Ramadan, Mater. Sci. Forum 550, 217 (2007)

[12] F.Q. Yang, R.B. Song, L.F. Zhang, C. Zhao, Proc. Eng. 81, 456 (2014)

[13] X.F. Zhang, H. Yang, D.P. Leng, L. Zhang, Z.Y. Huang, G. Chen, J. Iron. Steel Res. Int. 23(9), 963 (2016)

[14] Z.J. Miao, A.D. Shan, W. Wei, L.U. Jun, W.L. Xu, H.W. Song, Trans. Nonferrous Met. Soc. China 21(2), 236 (2011)

[15] A. Pinol-Juez, A. Iza-Mendia, I. Gutierrez, Metall. Mater. Trans. A 31(6), 1671 (2000)

[16] B.S. Xie, Q.W. Cai, W. Yu, L.X. Xu, Z. Ning, Acta Metall. Sin. (Engl. Lett.) 30(3), 250 (2017)

[17] J. Chen, H.T. Li, J.P. Hu, W.H. Yu, Hot Working Technol. 43(9), 64 (2014)

[18] T. Yan, E.L. Yu, Y.Q. Zhao, Iron Steel 48(9), 58 (2013) 
[19] L. Chen, L.M. Wang, X.J. Du, X. Liu, Acta Metall. Sin. 46, 52 (2010) (in Chinese)

[20] B.J. Yu, X.J. Guan, L.J. Wang, Q.K. Zeng, Q.Q. Liu, Y. Cao, Acta Metall. Sin. (Engl. Lett.) 24(4), 287 (2014)

[21] B.S. Xie, Q.W. Cai, W. Yu, L.X. Xu, Z. Ning, J. Mater. Eng. Perform. 25(12), 5127 (2016)

[22] D. Samantaray, S. Mandal, C. Phaniraj, A.K. Bhaduri, Mater. Sci. Eng. A 528(29), 8565 (2011)

[23] Z. Fei, S. Jian, X.D. Yan, J.L. Sun, J. Na, Z. Hua, Acta Metall. Sin. 50(6), 691 (2014) (in Chinese)

[24] C.L. Zhu, J.B. Zhang, C.Q. Cheng, J. Zhao, Acta Metall. Sin. 49(10), 1275 (2013) (in Chinese)

[25] C.J. Wang, K.K. Deng, S.S. Zhou, W. Liang, Acta Metall. Sin. (Engl. Lett.) 29(6), 527 (2016)

[26] G.Y. Lin, Z.F. Zhang, H. Zhang, D.S. Peng, J. Zhou, Acta Metall. Sin. (Engl. Lett.) 21(2), 109 (2008)

[27] A. Momeni, K. Dehghani, Mater. Sci. Eng. A 528(3), 1448 (2011)

[28] Y.P. Li, R.B. Song, E.D. Wen, F.Q. Yang, Acta Metall. Sin. (Engl. Lett.) 29(5), 441 (2016)

[29] S. Kingklang, V. Uthaisangsuk, Metall. Mater. Trans. A 48(1), 95 (2017)

[30] X. Ma, C.W. Zheng, X.G. Zhang, D.Z. Li, Acta Metall. Sin. (Engl. Lett.) 29(12), 1127 (2016)

[31] H. Farnoush, A. Momeni, K. Dehghani, J. Aghazadeh Mohandesi, H. Keshmiri, Mater. Des. 31(1), 220 (2010)
[32] J.R. Li, G. Chen, C. Lie, H. Zuo, Y.Z. Liu, Acta Metall. Sin. 50(9), 1063 (2014) (in Chinese)

[33] J. Johansson, M. Odén, Metall. Mater. Trans. A 31(6), 1557 (2000)

[34] P. Cizek, B.P. Wynne, W.M. Rainforth, J. Phys. Conf. Ser. 26(1), 331 (2006)

[35] Y.Q. Ning, T. Wang, M.W. Fu, M.Z. Li, L. Wang, C.D. Zhao, Mater. Sci. Eng. A 642, 187 (2015)

[36] I.S. Nikulin, N.V. Kamyshanchenko, T.B. Nikulicheva, M.V. Mishunin, K.A. Vokhmyanina, Mater. Lett. 182, 253 (2016)

[37] Z.Y. Liu, T.T. Huang, W.J. Liu, S.B. Kang, Trans. Nonferrous Met. Soc. China 26(2), 378 (2016)

[38] D.J. Li, Y.R. Feng, S.Y. Song, Q. Liu, Q. Bai, F.Z. Ren, F.S. Shangguan, J. Alloys Compd. 618, 768 (2015)

[39] M. Ma, H. Ding, Z.Y. Tang, J.W. Zhao, Z.H. Jiang, G.W. Fan, J. Iron. Steel Res. Int. 23(3), 244 (2016)

[40] I. Alvarez-Armas, M.C. Marinelli, S. Hereñú, S. Degallaix, A.F. Armas, Acta Mater. 54(19), 5041 (2006)

[41] Y. Liu, H. Yan, X. Wang, M. Yan, Mater. Sci. Eng. A 575, 41 (2013)

[42] A. Mohamadizadeh, A. Zarei-Hanzaki, H.R. Abedi, S. Mehtonen, D. Porter, Mater. Charact. 107, 293 (2015)

[43] D. Samantaray, S. Mandal, M. Jayalakshmi, C.N. Athreya, A.K. Bhaduri, V. Subramanya Sarma, Mater. Sci. Eng. A 598, 368 (2014) 